Research Article

\title{
Dynamic Mechanical Characteristics of Fractured Rock Reinforced by Different Grouts
}

\author{
Siming Kao $\mathbb{D}$, Guangming Zhao $\left(\mathbb{D}\right.$, Xiangrui Meng, Yingming Li $\mathbb{D}^{\mathbb{D}}$, Zenghui Liu, \\ Ruofei Zhang, Jun Zhou, and Shunjie Huang
} State Key Laboratory of Mining Response and Disaster Prevention and Control in Deep Coal Mines,
Anhui University of Science and Technology, Huainan 232001, China

Correspondence should be addressed to Guangming Zhao; guangmingzhao@163.com

Received 28 September 2020; Revised 25 November 2020; Accepted 17 January 2021; Published 29 January 2021

Academic Editor: Zhi Cheng Tang

Copyright (c) 2021 Siming Kao et al. This is an open access article distributed under the Creative Commons Attribution License, which permits unrestricted use, distribution, and reproduction in any medium, provided the original work is properly cited.

In order to investigate the dynamic mechanical properties of the fractured rocks reinforced with different slurries, the prefractured and grouted sandy mudstone specimens were tested on a Split Hopkinson Pressure Bar (SHPB), and their dynamic failure processes were shot via a high-speed camera. The test results showed that under dynamic loading, grouting reinforcement can relieve the rock failure at the fracture part. With the increase of the impact speed, the dynamic specific strength of the modified epoxy resin grouting increases from 0.85 to 1.01, and its specific strain rate increases from 1.09 to 1.04 ; the dynamic specific strength and specific strain rate of cement slurry grouting increase from 1.78 to 0.95 and from 0.60 to 0.98 , respectively. As a whole, the specimen reaches or approaches the dynamic parameters of the intact rock specimen after grouting repair, the stability of the rock reinforced by modified epoxy resin grouting is superior to that of the rock reinforced by cement slurry grouting, and the latter can acquire high dynamic strength under low-speed impact. The improved damage-type Zhuwangtang (ZWT) model can be used to describe the dynamic mechanical behaviors of the fractured rocks reinforced by grouting very well.

\section{Introduction}

During the deep coal mining and tunneling process, the mining activity breaks the original mechanical equilibrium. According to the theory of loose circle of surrounding rocks [1], a crushed zone will appear within a certain range of the roadway, and many fractures exist in the surrounding rock mass. If the fractured zone is not properly disposed, the original fractured zone may further evolve into a crushed zone due to the impact load generated by blasting in the construction, vibrating effect of surrounding rocks tunneled by heading machine, and the impact formed by roof fracture of the coal seam, and thus the support difficulty will be further aggravated. The grouting construction method can improve the physical and mechanical properties of the reinforced surrounding rocks and block the original fractures, so as to improve the overall strength and stability of the surrounding rocks. Therefore, the grouting construction method has been extensively applied in engineering practice.
The grouting reinforcement of rock mass has been extensively investigated both in China and western countries. In the aspects of rock grouting reinforcement mechanism and repair of fractured rocks, it is deemed that after grouting reinforcement, the residual strength [2] and peak shear strength [3] of the rock mass will be improved, the nondeformability will be strengthened, and the grouting concretion stone can keep stable bearing capacity within a large range. Although the rock strength will be improved after it is reinforced by common grouting materials such as cement slurry, polyurethane, and epoxy resin [4-6], different slurries exert different reinforcing effects on rocks or rock-like materials, and they differ in slurry groutability, initial strength and cohesiveness to rocks, etc. Among the factors influencing the grouting reinforcement, the slurry diffusion laws during the construction and slurry stability after the construction are also very important, so investigating the slurry diffusion laws under all kinds of conditions [7-10] and quantitatively evaluating the slurry stability [11] under 
different grouting parameters will be of great importance. As the geological environment for grouting is ever-changing, the individual demands for grouting materials in engineering are increasing year by year, and regarding slurry groutability, controllability, stability, and durability and economical efficiency, many scholars have developed newtype grouting materials, made modifications, and achieved abundant results [12-15]. The dynamic characteristics of grouting concretion stones with different grouting contents and moisture contents have been probed in recent years [16].

Most of the above research studies focus on the improvement of static mechanical properties of rock mass after grouting reinforcement, the grouting reinforcement effect, slurry diffusion laws, and slurry modification. These research studies are significant for revealing the rock grouting reinforcement mechanism and improving the grouting reinforcement effect. However, few studies have focus on the impact resistance of fractured rock mass after grouting reinforcement under different strain rates, the reinforcing effects of different slurries on fractured rock mass, and failure laws of fractured rock mass and those of fractured rock mass after grouting reinforcement under the dynamic impact load. After grouting, the fractured rock mass may bear blasting impact load, roof fracture impact, and dynamic disturbance of heading machine. The range of dynamic load strain rate is large and the impact strength is high, which will usually result in secondary failure of fractured rock mass after grouting reinforcement. Hence, it is urgent to explore into the impact resistance and failure laws of fractured rock mass after grouting reinforcement, and then studying the dynamic characteristics of fractured rock masses reinforced by different slurries under different strain rates will be of great realistic significance.

In this paper, the sandy mudstone specimens were preset fractures manually, and the fractures were filled with cement slurry and modified epoxy resin slurry. An impact test of fractured rock masses reinforced by different grouting materials was carried out under different strain rates on a Split Hopkinson Pressure Bar (SHPB), and their dynamic failure process was captured via a high-speed camera. The results contributed to understanding of the dynamic failure laws of fractured surrounding rocks, revealed the impact resistance of fractured rock masses reinforced with different slurries under different strain rates, and provided a reference for the grouting reinforcement engineering for fractured rock mass.

\section{Test Materials and Test Method}

2.1. Test Materials. The rock used in the test was common sandy mudstone in coal mining and tunnel engineering. The rock masses were collected from Luling Coal Mine of the Huaibei Mining Group with burial depth of $-580.5 \mathrm{~m}$, density of $2,560 \mathrm{~kg} \times \mathrm{m}^{-3}$, and uniaxial compressive strength of $22.5 \mathrm{MPa}$.

2.2. Test Method. The rock cores of intact rock masses with good homogeneity were taken using a vertical core drilling machine. The rock cores were cut with a rock cutter according to the length slightly greater than the design size. The specimens were processed according to rock mechanics test requirements, and the two end faces of each specimen were grinded with SHM-200 double-end-face grinding machine until its nonparallelism and nonperpendicularity were both not smaller than $0.02 \mathrm{~m}$. The processed specimen is $30 \mathrm{~mm}$ in length and $50 \mathrm{~mm}$ in diameter. To mitigate the impact of fracture size on the specimens, a $0.2 \mathrm{~mm}$ fracture was cut from the cross section of each specimen with the cutter, and the cutting depth was one half of the specimen diameter. The specimens with cut fractures were grouped, where one group was kept in original shape; one group was filled with neat cement grout (water cement ratio: 0.6), and the cement was ordinary Portland cement with mark of P.O 42.5; another group was filled with high-permeability modified epoxy resin grouting material, which was doublecomponent grouting material, where material A was the prepared epoxy resin and material B was curing agent, and their mixing ratio was $2: 1$.

The specimen was intertwined for one circle using adhesive tape before grouting, and a grouting hole was reserved at the top. The mixed slurry was slowly injected into the fracture with an injector and gently vibrated with $0.1 \mathrm{~mm}$ steel wire to eliminate the gas sealed in the fracture. After the fracture was fully filled with the slurry, the hole mouth was kept upward for $24 \mathrm{~h}$, the cement and epoxy resin were initially coagulated, and the external adhesive tape was taken down for the sake of curing. The cement grouting specimens were cured in a standard curing box while epoxy resin grouting specimens were cured at normal temperature. After 28 days of curing, the wave velocity of each specimen is measured, and the specimens with obvious abnormal wave velocity are excluded. The three types of specimens are shown in Figure 1.

2.3. Test System and Test Principle. Bars and punches used in the SHPB test system (Figure 2) are 40Cr alloy steels, density is $7,800 \mathrm{~kg} \cdot \mathrm{m}^{-3}$, yield strength is greater than $800 \mathrm{MPa}$, elastic wave velocity $C_{0}$ is $5,410 \mathrm{~m} \cdot \mathrm{s}^{-1}$, bar diameter is $50 \mathrm{~mm}$, and lengths of the incident bar and transmitting bar are $2.00 \mathrm{~m}$ and $1.50 \mathrm{~m}$, respectively. Punches are coneshaped punches recommended by the International Society for Rock Mechanics [17], and its maximum diameter is $50 \mathrm{~mm}$. According to $1 \mathrm{D}$ elasticity theory of waves, average stress, average strain, and average strain rate of samples can be obtained [18], namely,

$$
\begin{aligned}
& \sigma_{s}(t)=\frac{E A}{2 A_{s}}\left[\varepsilon_{I}(t)+\varepsilon_{R}(t)+\varepsilon_{T}(t)\right], \\
& \varepsilon_{s}(t)=\frac{C_{0}}{L_{s}} \int_{0}^{t}\left[\varepsilon_{T}(t)-\varepsilon_{I}(t)+\varepsilon_{R}(t)\right] \mathrm{d} t, \\
& \dot{\varepsilon}_{s}(t)=\frac{C_{0}}{L_{s}}\left[\varepsilon_{T}(t)-\varepsilon_{I}(t)+\varepsilon_{R}(t)\right],
\end{aligned}
$$

where $L_{s}$ is the sample length; $E$ is the elasticity modulus of the incident (transmitting) bar; $A$ and $A_{s}$ are the cross- 


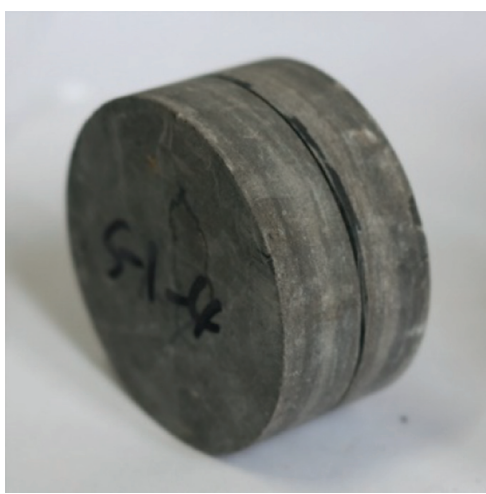

(a)

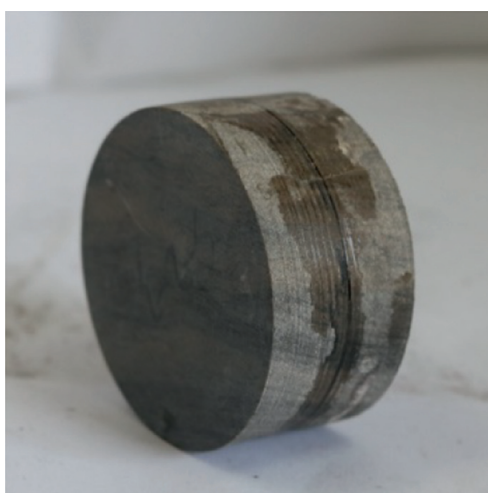

(b)

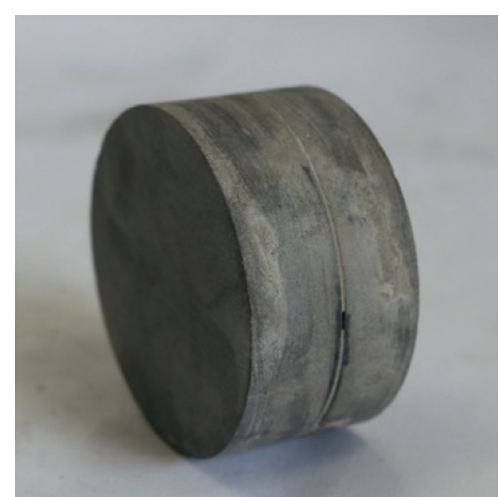

(c)

FIgURE 1: Specimens: (a) fracture specimen, (b) modified epoxy resin grouting, and (c) cement grouting.

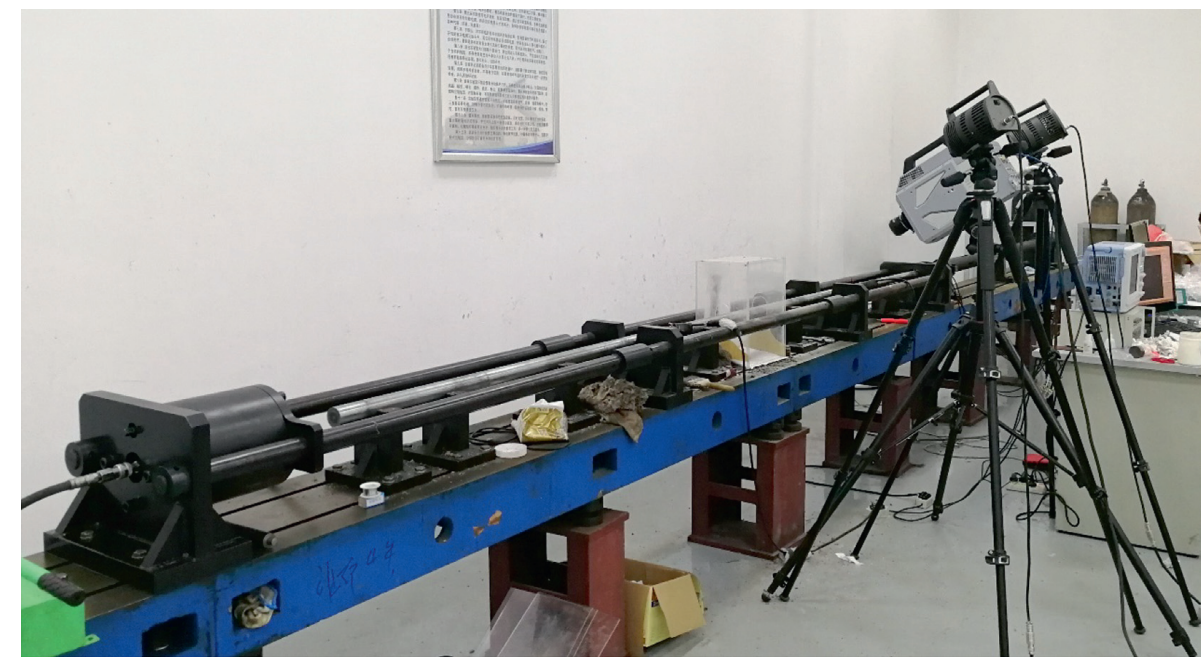

FIGURE 2: SHPB test system.

sectional area of the incident (transmitting) bar and the sample; $\varepsilon_{I}(t)$ is the incident wave strain signal; $\varepsilon_{R}(t)$ is the reflected wave strain signal; $\varepsilon_{T}(t)$ is the transmitted wave strain signal. To prevent the influence of stress unbalance on the test result, data are processed in this test through the " 3 wave analysis" method.

2.4. Testing Program. The processed and cured specimens were grouped and numbered. To keep the acquired impact speeds of specimens in different groups under the same atmospheric pressure as consistent as possible, the test started from a low atmospheric pressure level. After the specimens in Group A, B, C, and D were tested under fixed atmospheric pressure, the test was continued by elevating the atmospheric pressure to the next pressure level. The concrete testing program is seen in Table 1.

\section{Results and Discussion}

3.1. Dynamic Stress Equilibrium. A reliable dynamic test should ensure that the dynamic stress equilibrium before the specimen is destroyed [19]. Therefore, it is necessary to check the dynamic stress equilibrium to ensure the validity of the test. The dynamic stress at both ends of the specimen during the loading process can be obtained by the strain gauge on the bar. It can be seen from the curve that the stress at the transmission end of the specimen is less than that at the incident end within $25 \mu$ s at the initial loading stage. During this period, the stress wave was reflected in the specimen for many times, and the dynamic stress at both ends of the specimen reached a state of equilibrium, while the stress equilibrium time was less than the failure time of the specimen, thus ensuring that the failure of the specimen occurred after the stress equilibrium. The typical dynamic stress at both ends of the specimen is shown in Figure 3.

\subsection{Influence of Grouting Reinforcement on Dynamic Stress-} Strain Relationship of Fractured Rock Mass. As an important index used to study material properties, the stress-strain relationship of a material is its own mechanical property, which can reflect its deformation and failure laws under the external loading action. The impact failure laws of fractured rock can be judged, and the rock grouting reinforcement effect can be verified through the dynamic stress-strain relationship. 
TABle 1: Test scheme.

\begin{tabular}{|c|c|c|c|c|c|c|c|}
\hline \multirow{2}{*}{ Group } & \multirow{2}{*}{ Specimen form } & \multirow{2}{*}{ Grouting material } & \multicolumn{5}{|c|}{ Number of specimens } \\
\hline & & & $0.2 \mathrm{MPa}$ & $0.4 \mathrm{MPa}$ & $0.6 \mathrm{MPa}$ & $0.8 \mathrm{MPa}$ & $1.0 \mathrm{MPa}$ \\
\hline $\mathrm{A}$ & Complete & None & 3 & 3 & 3 & 3 & 3 \\
\hline B & Prefracture & None & 3 & 3 & 3 & 3 & 3 \\
\hline $\mathrm{C}$ & Prefracture & Cement slurry & 3 & 3 & 3 & 3 & 3 \\
\hline $\mathrm{D}$ & Prefracture & Modified epoxy resin & 3 & 3 & 3 & 3 & 3 \\
\hline
\end{tabular}

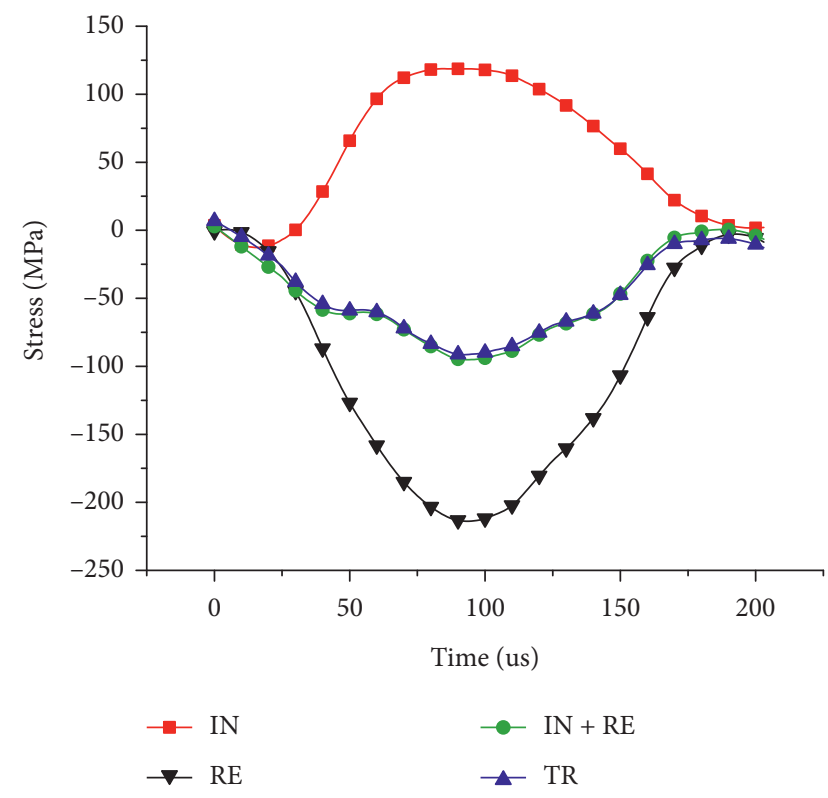

Figure 3: Typical dynamic stresses on both ends of specimen.

The delay time was calculated according to the specimen length, distance from strain gauge to bar end, and the wave propagation velocity in incident bar and transmission bar and specimen. The initial positions of wave forms were aligned through the translation waveform method, and the parameters of impact specimens such as stress and strain were calculated using the three-wave model. The stressstrain relationships of intact rock, fractured rock, fractured specimen filled with epoxy resin, and fractured specimen filled with cement slurry under gas pressure of $0.6 \mathrm{MPa}$ are shown in Figure 4.

It could be observed from the stress-strain relation curves of all specimens under the same pressure that except for the stress-strain relation curve of the fractured specimen, the stress-strain relation curve shapes of other three specimens were basically similar and largely divided into four phases: elastic phase, below $60 \mathrm{MPa}$, was a straight-line part, at the time the stress and strain were under linear relation, and this linear relation might not be kept nearby $60 \mathrm{MPa}-100 \mathrm{MPa}$, which should be the elastic limit of the specimen. Following elastic phase, there was a slightly flat part, namely, yield phase. After the yield phase, the stressstrain relation curve continued to rise until the limit of peak strength, namely, strengthening phase. Afterwards, each of the specimens would enter failure phase. Due to the existence of fracture, initial fracture occurred at the bottom of

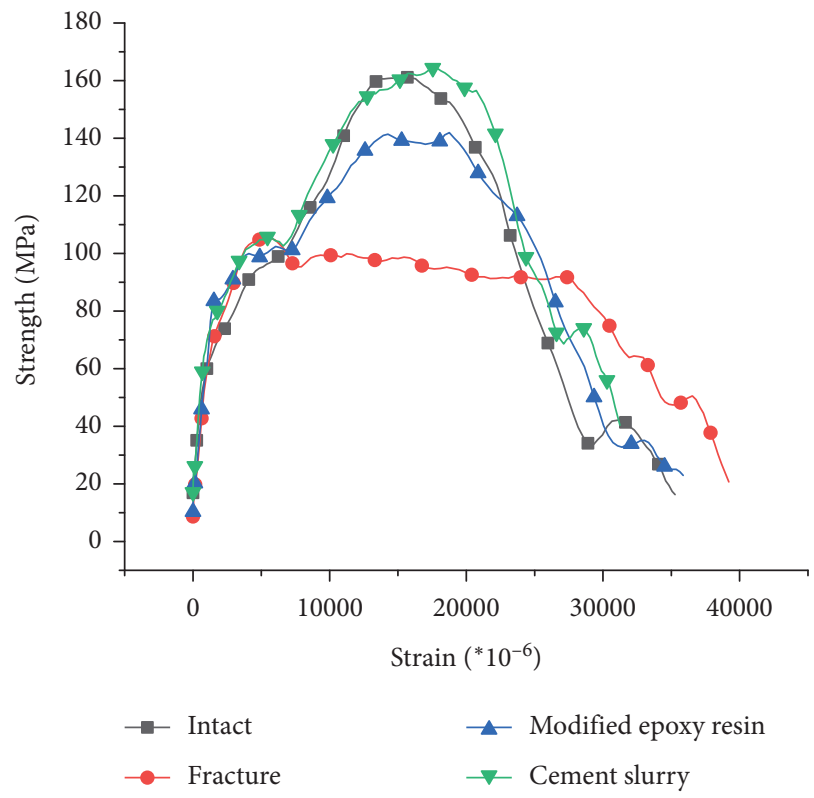

FIGURE 4: Stress-strain curve of four types of specimens (0.6 MPa).

the fracture of the fractured specimen after it entered the yield phase, and the stress firstly declined and then was kept unchanged, while the strain continued to increase without strengthening phase until secondary failure. Under lowspeed impact with atmospheric pressure of $0.6 \mathrm{MPa}$, the peak strength of the fractured specimen filled with cement slurry was reached and even exceeded the peak strength of intact rock, but the peak strength of the fractured specimen filled with modified epoxy resin was somehow lower. The stress-strain curve of the fractured specimen filled with modified epoxy resin was flat at the peak point, indicating that the modified epoxy resin exerted a certain buffering effect on the fracture under low-speed impact. It could be intuitively seen from the stress-strain curves that the grouting reinforcement by filling the fracture could improve the mechanical properties of the rock and reach or approach the status of the original intact rock.

3.3. Influence of Grouting Reinforcement on Dynamic Peak Strength of Fractured Rock Mass. The dynamic compressive strength of rock is an important index reflecting its impact resistance. The effect of grouting reinforcement on the fractured rock can be judged through its strength. The average dynamic strength of specimens in each group was calculated, and the impact speed-peak strength relation curve was drawn as shown in Figure 5. 


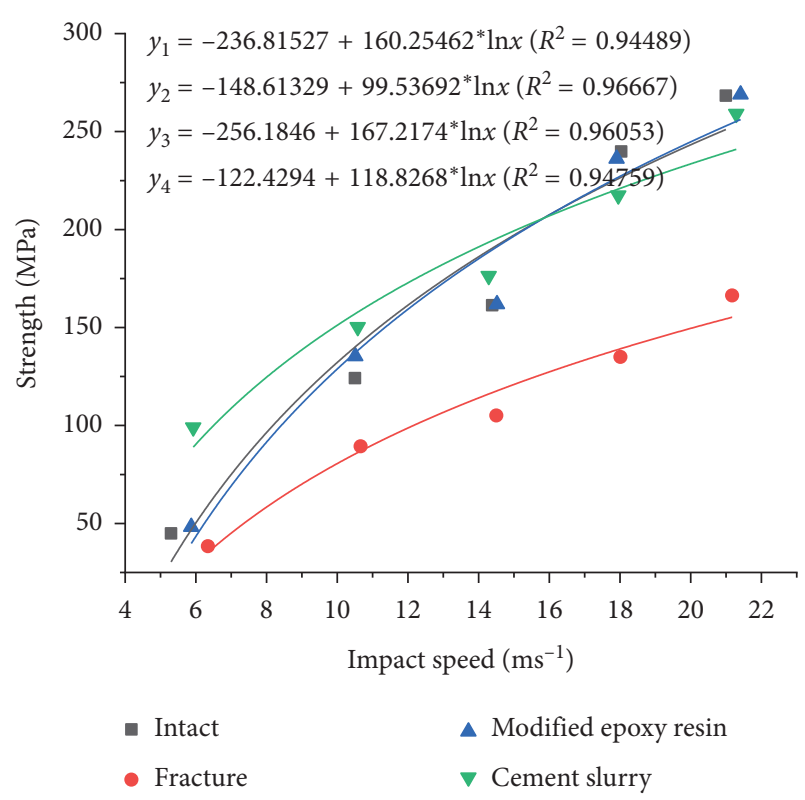

FIGURE 5: Impact speed and strength.

As shown in Figure 5, the peak strengths of the intact rock specimen, fractured rock specimen, and fractured specimen filled with slurry presented a natural logarithmic relationship with the impact speed of the punch. The strength of the fractured rock specimen was smaller than those of other three specimens under all impact speeds, and the strength gap was enlarged with the increase of impact speed. Taken the peak strength curve of the intact rock specimen as the reference, the peak strength curve of the specimen filled with epoxy resin was approximately overlapped with that of the intact specimen, indicating that the fracture filling with epoxy resin could effectively recover the strength of the fractured rock. Though being able to improve the strength of the fractured rock, fracture filling with cement slurry showed different properties from epoxy resin filling. Under low impact speed, the peak strength of the fractured rock filled with cement slurry was higher than that of the intact rock specimen. When the impact speed was elevated to above $16 \mathrm{~m} / \mathrm{s}$, the peak strength of the fractured rock filled with cement slurry was lower than that of the intact rock. The main reason was that microfractures would be formed at the filling interface after the cement slurry with high dry shrinkage rate was totally cured, and then the cement slurry filled specimen and fractured specimen shared approximate properties which could also be proved through the curve shape. Due to the existence of the microfractures, the microfractures had enough time to be closed under low-speed impact. As the strength of the filling cement was higher than that of sandy mudstone, its peak strength was higher than that of the intact sandy mudstone. The impact strain rate was high under high-speed impact, so the specimen that already underwent a failure before the microfractures were closed, the specimen strength bore greater influence from the fractures than from the strain rate, and thus the peak strength was slightly smaller than that of the intact specimen.

In the natural logarithm of impact speed taken as the $x$ coordinate and peak strength as the $y$-coordinate, the curve is drawn as seen in Figure 6.

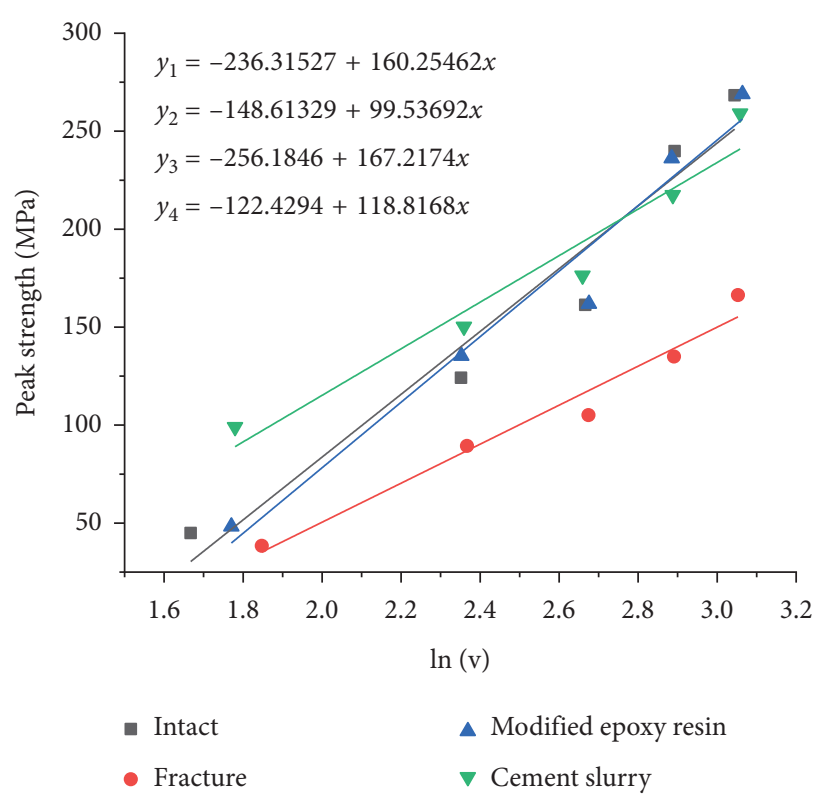

FIGURE 6: Logarithm of impact speed and peak strength.

The following was set:

$$
k_{1}=\frac{d \sigma}{d \ln (v)} .
$$
follows:

The slope of each fitting straight line could be solved as

$$
\begin{aligned}
k_{\text {int }} & =160.25462, \\
k_{\text {fra }} & =99.53692, \\
k_{\text {epo }} & =167.2174, \\
k_{\text {cem }} & =118.8168 .
\end{aligned}
$$

The straight slope (167.2174) of the specimen filled with epoxy resin was approximate to that (160.25462) of the intact specimen, and the two specimens had equivalent dynamic properties; the straight slope (118.8168) of the specimen filled with cement slurry was approximate to that (99.53692) of the fractured specimen, and their dynamic properties were approximate.

Taken the slope $k$ value of the strength curve of the intact rock as the criterion, the factor reflecting the repair degree of other specimens was defined as follows:

$$
\gamma_{a i}=\frac{k_{i}}{k} \times 100 \%
$$

The repair factors of the specimens were calculated as seen in Table 2.

Through statistical Table 2, the fractured sandy mudstone filled with epoxy resin had equivalent properties to the original intact rock as a whole: the favorable reinforcement effect could be achieved, while the reinforcement effect of cement slurry was not as good as epoxy resin.

According to the fitted curve of test data, the peak strengths under different speeds were calculated. Taken the strength value of the intact specimen under each impact 
TABLE 2: Statistical table of specimen repair factor $\gamma_{a}$.

\begin{tabular}{lcccc}
\hline Category & Intact & Fracture & Modified epoxy resin & Cement slurry \\
\hline$k$ & 160.25462 & 99.53692 & 167.2174 & 118.8168 \\
$\gamma_{a}$ & $100 \%$ & $62.11 \%$ & $104.34 \%$ & $74.14 \%$ \\
\hline
\end{tabular}

speed as the criterion, the dynamic specific strength factor was defined as follows:

$$
\eta_{i}=\frac{\sigma_{i}}{\sigma_{0 i}}
$$

The strength values of all specimens under different impact speeds were normalized (Table 3), and the dynamic specific strength factor-impact speed relation curve was drawn as shown in Figure 7.

By analyzing Table 3 and Figure 7, it can be obviously observed that the dynamic specific strength of the fractured specimen was approximately 0.6 , that of the specimen filled with epoxy resin was 0.85 at low speed and 1 at both medium and high speed, and that of the specimen filled with cement slurry was 1.7 at low speed, declined to 1.00 or so at $16 \mathrm{~m} / \mathrm{s}$, and then was gradually reduced as the impact speed was further accelerated. The dynamic strength of the fractured specimen filled with cement slurry was superior to that of the specimen filled with epoxy resin under low-speed impact, but the situation was on the contrary under high-speed impact, and moreover, the properties of the specimen filled with epoxy resin were close to those of the intact specimen.

\subsection{Influence of Grouting Reinforcement on Strain Rate of} Fractured Rock Mass. Strain rate refers to the strain (deformation) change of a material relative to time, and it is a measure used to characterize the material deformation speed. The strain rate is related to both impact speed and material properties. Studies show that the dynamic impact strength is high at high strain rate. The strain rate-impact speed relations embodied in different specimens are displayed in Figure 8.

The middle flat parts were intercepted from the strain rate-time relation curves of the specimens as the samples, and the mean value of each specimen was taken as its strain rate. From the strain rate-impact speed relation curves, the strain rate of each specimen presented a linear relation with impact speed, namely, it was gradually increased with the impact speed, but the straight slope varied.

The following was set:

$$
k_{i}^{\prime}=\frac{\mathrm{d} \dot{\varepsilon}}{\mathrm{d} v}
$$

The slope of each fitting straight line was as follows:

$$
\begin{aligned}
& k_{\text {int }}^{\prime}=20.94325, \\
& k_{\text {fra }}^{\prime}=25.5988, \\
& k_{\text {epo }}^{\prime}=21.37621, \\
& k_{\text {cem }}^{\prime}=23.87668 .
\end{aligned}
$$

The slope of the fractured specimen was the maximum, 25.59881 , and its strain rate was most obviously influenced by the impact speed. Because of the fracture, it could acquire greater strain under impact pressure, and thus its strain rate was higher than other specimens. The straight slope of the strain rate was 23.87668 for the cement slurry filled specimen, as microfractures would be formed after dry shrinkage of cement slurry. This type of specimen showed the characteristics of the fractured specimen, and its slope was also close to that of the fractured specimen, but its strain rate was lower, mainly because both strength and stiffness of the induration of cement slurry used to fill the specimen were larger than those of sandy mudstone. For the specimen filled with epoxy resin and the intact specimen, the straight slopes of strain rates were 21.37621 and 20.94325 , respectively, which were quite close, along with equivalent properties. The straight slope of strain rate of the specimen filled with epoxy resin was slightly greater than that of the intact rock specimen, because the fracture filler was modified epoxy resin which was of a certain tenacity with hardness smaller than rock, and it could be easily deformed during the impact process.

Similarly, the slope $k^{\prime}$ value of the strain rate curve of the intact rock was taken as the criterion, and the factor used to reflect the repair degree of other specimens was defined as follows:

$$
\gamma_{b i}=\frac{1}{\left(k_{i}^{\prime} / k^{\prime}\right)} \times 100 \%
$$

The damage repair factor of each specimen was calculated as seen in Table 4.

As seen in Table 4, in consideration of the overall strain rate, the repair degree of the fractured specimen filled with epoxy resin was approximate to the intact specimen, followed by the specimen filled with cement slurry. The main reason lied in that the epoxy resin filling material could be closely adhered to the specimen by virtue of high fluidity and high viscosity but low dry shrinkage rate. However, the cement slurry with poor fluidity was prone to bubbling, the shrinkage rate could be high after curing, and a weak plane could be easily generated on the surface of the filled fracture. This could be observed from Figures 9 and 10 after the specimen underwent crushing. The filling interface was separated from the specimen filled with cement slurry, indicating poor cohesive force of cement slurry. It could be seen from the separated grouting surface that the cured body of the slurry contained a small quantity of bubbles. For the specimen filled with epoxy resin, the cured slurry was still adhered to the specimen after the failure, while the failure degree at the nongrouting side was higher than that at the grouting side.

The strain rates under different impact speeds were calculated based on the fitted curves of their strain rate data. By taking the strain rate of the intact specimen as the criterion, the specific strain rate was defined as follows: 
TABLE 3: Statistical table of specimen strength and dynamic specific strength.

\begin{tabular}{|c|c|c|c|c|c|c|c|}
\hline \multirow{2}{*}{ Impact speed $\mathrm{ms}^{-1}$} & \multirow{2}{*}{ Strength (intact) (MPa) } & \multicolumn{2}{|l|}{ Fracture } & \multicolumn{2}{|c|}{ Modified epoxy resin } & \multicolumn{2}{|c|}{ Cement slurry } \\
\hline & & Strength $(\mathrm{MPa})$ & $\eta_{1}$ & Strength $(\mathrm{MPa})$ & $\eta_{2}$ & Strength $(\mathrm{MPa})$ & $\eta_{3}$ \\
\hline 6 & 50.82 & 29.73 & 0.59 & 43.43 & 0.85 & 90.46 & 1.78 \\
\hline 8 & 96.92 & 58.37 & 0.60 & 91.53 & 0.94 & 124.64 & 1.29 \\
\hline 10 & 132.68 & 80.58 & 0.61 & 128.85 & 0.97 & 151.16 & 1.14 \\
\hline 12 & 161.90 & 98.73 & 0.61 & 159.34 & 0.98 & 172.82 & 1.07 \\
\hline 14 & 186.61 & 114.07 & 0.61 & 185.11 & 0.99 & 191.13 & 1.02 \\
\hline 16 & 208.00 & 127.36 & 0.61 & 207.44 & 1.00 & 207.00 & 1.00 \\
\hline 18 & 226.88 & 139.09 & 0.61 & 227.14 & 1.00 & 221.00 & 0.97 \\
\hline 20 & 243.76 & 149.57 & 0.61 & 244.75 & 1.00 & 233.51 & 0.96 \\
\hline 22 & 259.04 & 159.06 & 0.61 & 260.69 & 1.01 & 244.84 & 0.95 \\
\hline
\end{tabular}

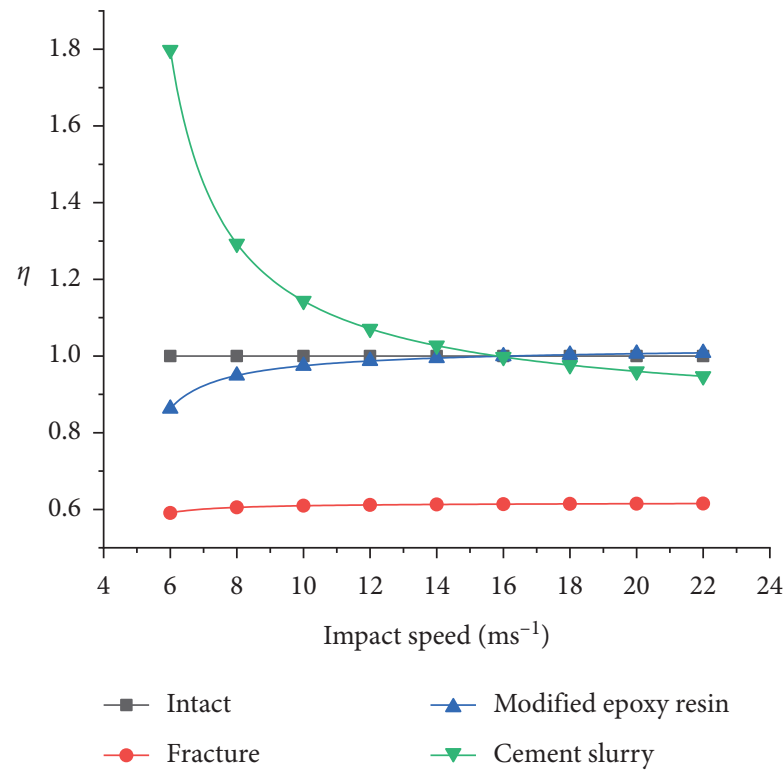

FIGURE 7: Impact speed-dynamic specific strength.

$$
\zeta_{i}=\frac{\dot{\varepsilon}_{i}}{\dot{\varepsilon}_{0 i}} .
$$

The strain rates of the specimens under different impact speeds were normalized, the statistical results are listed in Table 5, and the specific strain rate-impact speed relation curves were drawn (Figure 11).

As shown in Table 5 and Figure 11, the specific strain rate of the fractured specimen was approximately unchanged. And it kept an identical trend with the intact rock in the aspect of strain rate. Moreover, its strain rate was higher than that of the original rock. Relative to sandy mudstone, one between the two filling materials was hard and the other was soft with different change trends of their strain rates. With the impact speed increased, the specimen filled with epoxy resin showed a gradually declining specific strain rate, which was then approaching 1 , and the specific strain rate of the specimen filled with cement slurry gradually rose and also approximated to 1 . The specific strain rate of the specimen filled with cement slurry seemed to have stronger sensitivity to the impact speed, and the change was more evident, but the specific strain rate of the specimen filled with epoxy resin

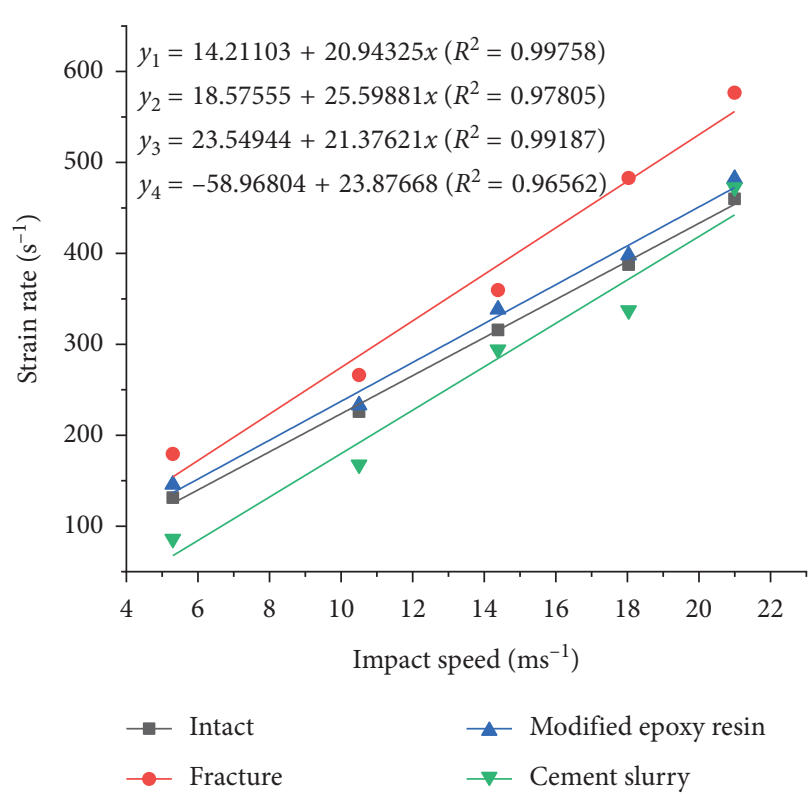

FIgURE 8: Impact speed-strain rate.

was always approximate to 1 , manifesting that the repaired rock was approximate to the intact rock in properties.

\subsection{Influence of Grouting Reinforcement on Failure Mode of Fractured Rock Mass}

3.5.1. Specimen Failure Mode. To understand the detailed failure laws of the specimen during the impact process, their impact failure processes were synchronously shot by using Phantom high-speed camera (NIKOR normal lens with NIKOR $50 \mathrm{~mm}$ focal length) produced by U.S. Vision Research, Inc., where the shooting frequency was 84,000 frames/second. The failure process of some specimens at an atmospheric pressure of $0.4 \mathrm{MPa}$ is shown in Figures 12-14.

As shown in Figure 12, the specimen was compressed at the end of the incident bar in the beginning. A new through fracture was formed at the middle fracture tip as the stress wave amplitude was gradually enlarged. Due to the existence of the middle fracture, the original support was eliminated after the new through fracture was formed, and the specimen part close to the incident bar rapidly moved and rushed at 
TABLE 4: Statistical table of specimen repair factor $\gamma_{b}$.

\begin{tabular}{lcccc}
\hline Category & Intact & Fracture & Modified epoxy resin & Cement slurry \\
\hline$k$ & 20.94325 & 25.59881 & 21.37621 & 23.87668 \\
$\gamma_{b}$ & $100 \%$ & $81.81 \%$ & $97.97 \%$ & $87.71 \%$ \\
\hline
\end{tabular}

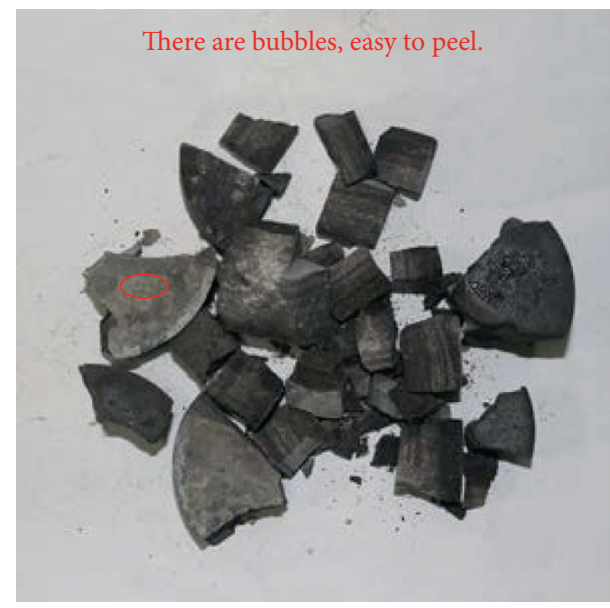

Figure 9: Cement slurry filling.

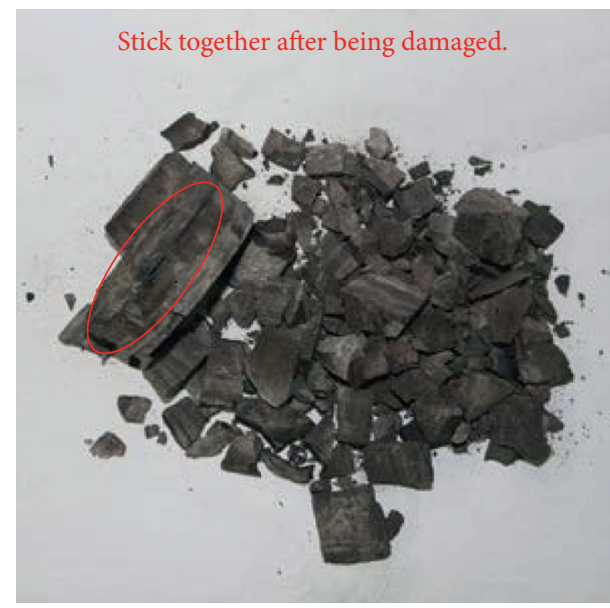

Figure 10: Modified epoxy resin filling.

the other side under the action of force at the end part. Influenced by the compressive stress on the end face of the new fracture and the pressure formed after the two end faces of the fracture contacted each other, fracturing occurred at the fracture end on the specimen part close to the end of the incident bar. After then, the whole specimen was under compaction state and jointly bore the subsequent impact load. Due to the new through fracture formed at the middle crack tip, the specimen on one side of the fracture first breaks into a large piece. Under the low-speed impact state, the large piece of specimen that broke along the fracture end could still be seen.

After grouting, both cured slurries could effectively fill the fracture and facilitate the recovery of the stress transfer path with a certain shrinkage space. Therefore, the initial specimen failure was delayed, and the failure part usually started from the nongrouting half and then stretched to the fracture tip until the grouting part. Under low-speed impact, the cured modified epoxy resin filler was of higher tenancy than cured cement, so was its cohesive force. Therefore the grouting side was kept relatively intact in comparison with the cement slurry filled specimen. Under high-speed impact, the loaded strain rate was high, the loading time was short, and the gap at the specimen fracture experienced compression failure before adjustment, so the gaps among the three specimens were not apparent, and the pictures of their failure processes were not displayed any longer.

3.5.2. Mechanism Analysis of Specimen Failure Mode. Assume that the stress-bearing conditions of one transient specimen after the stress equilibrium are shown in Figure 15(a). One part of the section where the fracture was located was intercepted as the study object, and uniform pressure $\sigma_{N}$ acted upon the section of the specimen connection part. According to the equilibrium of force system, the following could be acquired:

$$
\sigma_{N} \cdot \frac{\pi r^{2}}{2}-\sigma_{d} \cdot \pi r^{2}=0
$$

The following was then obtained:

$$
\sigma_{N}=2 \sigma_{d} .
$$

The upper part of the section $\mathrm{ABCD}$ is taken as the study object. Assume that shear force $F_{s}$ and bending moment $M$ exist on the section $\mathrm{ABCD}$ :

$$
\begin{aligned}
& F_{s}=2 \int_{0}^{r} \sigma_{d} \cdot \sqrt{r^{2}-x^{2}} \mathrm{~d} x, \\
& M=2 \int_{0}^{r} \sigma_{d} \cdot \sqrt{r^{2}-x^{2}} \cdot r \mathrm{~d} x .
\end{aligned}
$$

The integral transformation of the above two equations was implemented, and $x=r \sin \theta$ and $\mathrm{d} x=r \cos \theta \mathrm{d} \theta$ were set.

The following was then obtained:

$$
\begin{aligned}
& F_{s}=2 \sigma_{d} \int_{0}^{\pi / 2} r^{2} \cos ^{2} \theta \mathrm{d} \theta=\frac{1}{2} \pi r^{2} \sigma_{d}, \\
& M=2 \sigma_{d} \int_{0}^{\pi / 2} r^{3} \sin \theta \cos ^{2} \theta \mathrm{d} \theta=\frac{2}{3} r^{3} \sigma_{d} .
\end{aligned}
$$

As shear force and bending moment exist on the section $A B C D$, shear stress and positive tensile stress would certainly exist. Although the compressive stress $\sigma_{N}$ of the undamaged part was larger than other parts, the shear behavior of rock had a great influence on the stability of rock structure [20-23]. The shear strength and tensile strength of rock material were far lower than compressive strength, so the primary causes for failure were shear stress and tensile stress. In consideration of stress concentration at the fracture tip, it could be judged that the section $A B C D$ would be the first one to experience failure. The failure process of the 
TABLE 5: Statistical table of specimen strain rate and specific strain rate.

\begin{tabular}{|c|c|c|c|c|c|c|c|}
\hline \multirow{2}{*}{ Punch velocity $\left(\mathrm{ms}^{-1}\right)$} & \multirow{2}{*}{ Strain rate of intact $\left(\mathrm{s}^{-1}\right)$} & \multicolumn{2}{|l|}{ Fracture } & \multicolumn{2}{|c|}{ Modified epoxy resin } & \multicolumn{2}{|c|}{ Cement slurry } \\
\hline & & Strain rate $\left(\mathrm{s}^{-1}\right)$ & $\zeta_{1}$ & Strain rate $\left(\mathrm{s}^{-1}\right)$ & $\zeta_{2}$ & Strain rate $\left(\mathrm{s}^{-1}\right)$ & $\zeta_{3}$ \\
\hline 6 & 139.87 & 172.17 & 1.23 & 151.81 & 1.09 & 84.29 & 0.60 \\
\hline 8 & 181.76 & 223.37 & 1.23 & 194.56 & 1.07 & 132.05 & 0.73 \\
\hline 10 & 223.64 & 274.56 & 1.23 & 237.31 & 1.06 & 179.80 & 0.80 \\
\hline 12 & 265.53 & 325.76 & 1.23 & 280.06 & 1.05 & 227.55 & 0.86 \\
\hline 14 & 307.42 & 376.96 & 1.23 & 322.82 & 1.05 & 275.31 & 0.90 \\
\hline 16 & 349.30 & 428.16 & 1.23 & 365.57 & 1.05 & 323.06 & 0.92 \\
\hline 18 & 391.19 & 479.35 & 1.23 & 408.32 & 1.04 & 370.81 & 0.95 \\
\hline 20 & 433.08 & 530.55 & 1.23 & 451.07 & 1.04 & 418.57 & 0.97 \\
\hline 22 & 474.96 & 581.75 & 1.22 & 493.83 & 1.04 & 466.32 & 0.98 \\
\hline
\end{tabular}

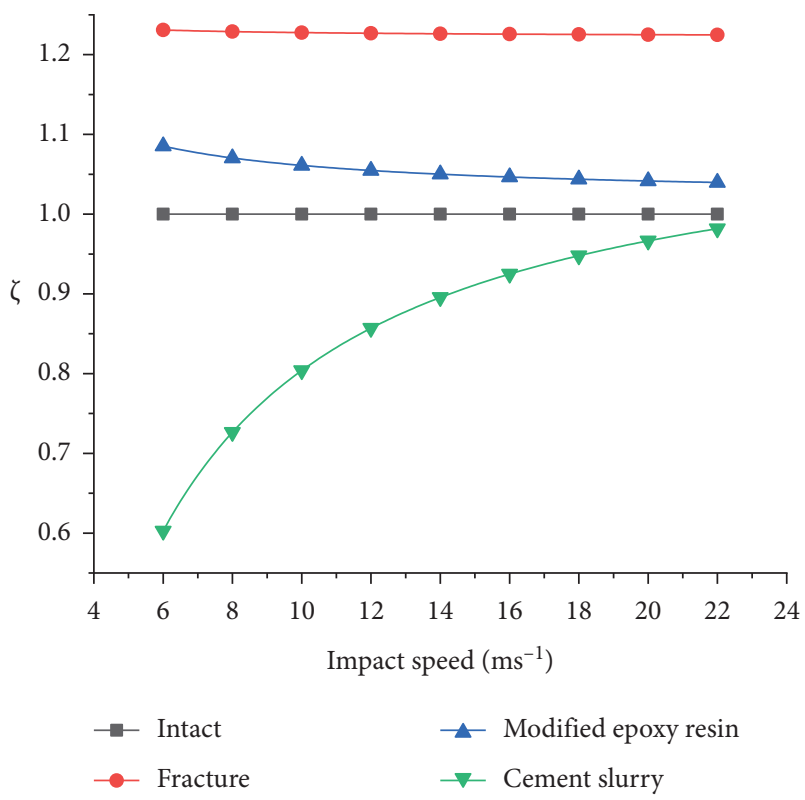

FIGURE 11: Impact speed-specific strain rate.

fractured specimen recorded by the high-speed camera rightly shows that the failure starts on this section.

After grouting reinforcement, the stress could be transferred at the fracture or microfractures which could be easily compacted, and they could transfer the stress after compaction. The following was obtained according to the principle of equilibrium:

$$
\sigma_{N 1}+\sigma_{N 2}=2 \sigma_{d}
$$

Assume that the two end faces of each specimen are always parallel during the initial loading process, and satisfy Hooke's law before failure:

$$
\begin{aligned}
& \sigma_{N 1}=E_{1} \cdot \varepsilon, \\
& \sigma_{N 2}=E_{2} \cdot \varepsilon .
\end{aligned}
$$

It is substituted into equation (18):

$$
\frac{1}{\sigma_{N 1}}=\frac{1}{2 \sigma_{d}}+\frac{1}{2 \sigma_{d}} \frac{E_{2}}{E_{1}}
$$

From equation (21), $\sigma_{N 1}$ is gradually reduced with the increase of $E_{2}$, suggesting that the fracture filling can effectively reduce the stress acting upon the intact rock. $\sigma_{N 1}=$ $\sigma_{d}$ when $E_{2}=E_{1} ; \sigma_{N 1}<\sigma_{d}$ when $E_{2}>E_{1}$, indicating that if the elasticity modulus of the cured grouting material is greater than rock, the stress borne by the grouting side will be larger than that at the intact side.

3.6. Establishment and Verification of Constitutive Relation of Grouting Reinforced Fractured Rock Mass. For brittle materials such as rock and concrete, their dynamic mechanical properties under impact load may differ a lot from their static mechanical properties, which is generally related to the strain rate. With one nonlinear elastomer and two Maxwell bodies, the ZWT model [24] can show viscous-elastic characteristics within a wide range of strain rate, and it can be used to describe the constitutive behaviors of nonlinear viscoelasticity of typical high polymers very well [25]. In view of characteristics of rock materials, such as fractures and gaps, many scholars have used the improved ZWT model [26-30] to simulate the mechanical behaviors of brittle materials such as rock at different strain rates. Under impact load, the strain rate of rock materials can be stabilized at a high level, so the Maxwell body describing low strain rate in the ZWT model was deleted in this study. In consideration of the strain softening behaviors of rock materials under impact action, a damage body was used to replace the nonlinear elastomer in the ZWT model, and an improved damage-type ZWT model was established for the grouting reinforced fractured rock mass (Figure 16).

Assume that the microelement strength of the damage body follows Weibull statistical distribution, and then the probability density function was

$$
\square p(\varepsilon)=\frac{m}{F_{0}}\left(\frac{\varepsilon}{F_{0}}\right)^{m-1} \exp \left[-\left(\frac{\varepsilon}{F_{0}}\right)^{m}\right],
$$

where $\varepsilon$ is a variable characterizing the microelement strength, and here it means axial strain; $m$ and $F_{0}$ are Weibull distribution parameters.

Hereby is a definition of damage variable:

$$
D=\frac{N_{f}}{N},
$$




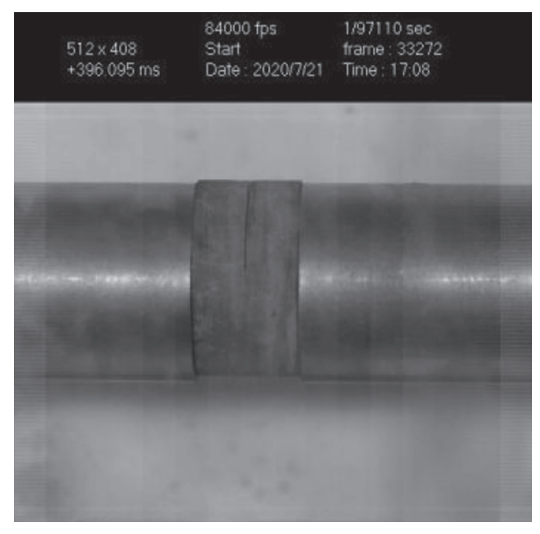

(a)

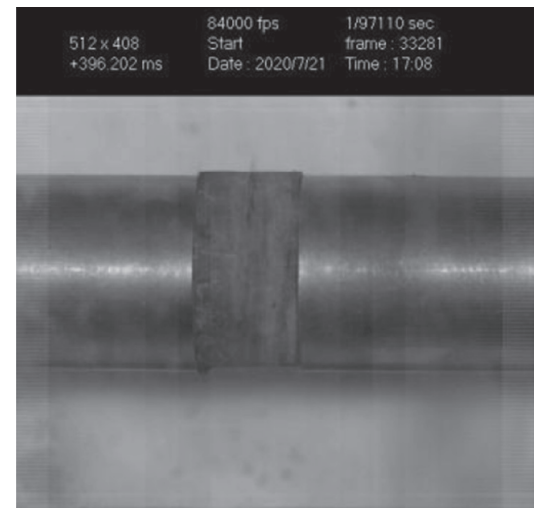

(d)

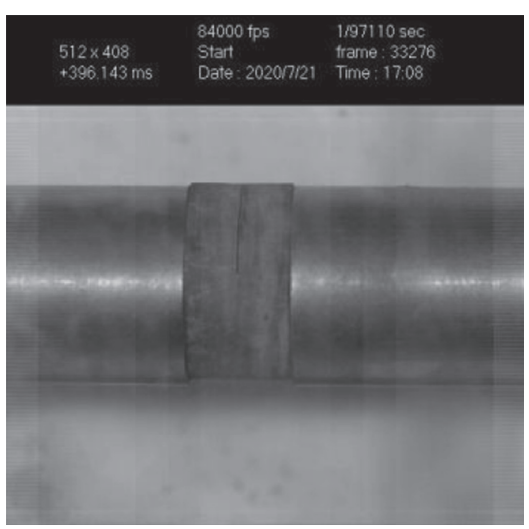

(b)

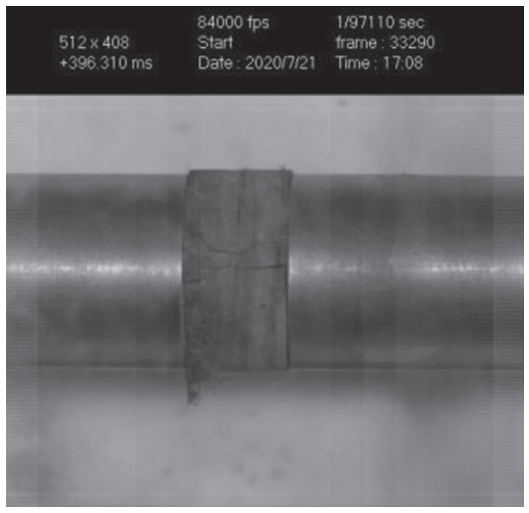

(e)

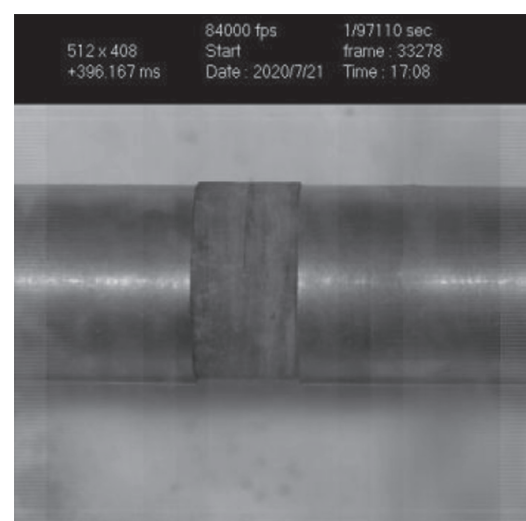

(c)

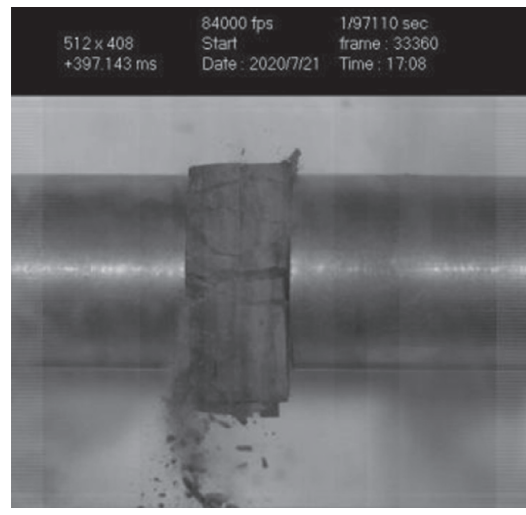

(f)

Figure 12: Failure of cracked specimen. (a) 0 us, (b) 48 us, (c) 72 us, (d) 107 us, (e) 215 us, and (f) 1048 us.

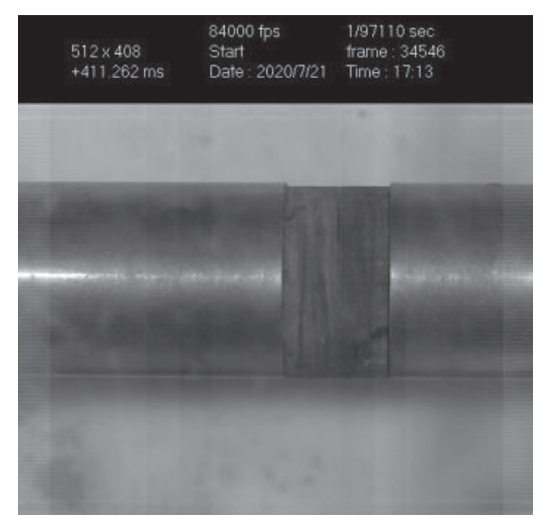

(a)

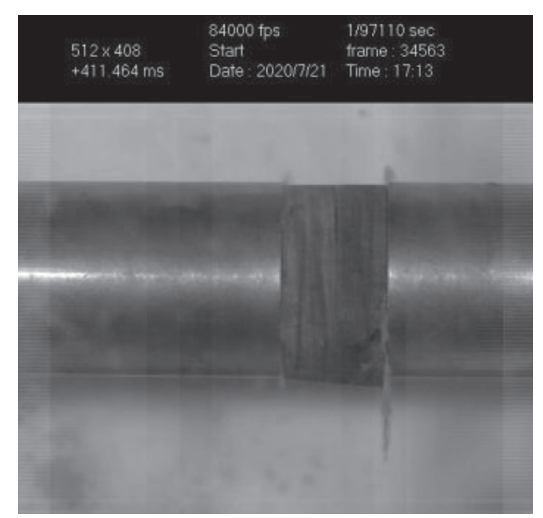

(d)

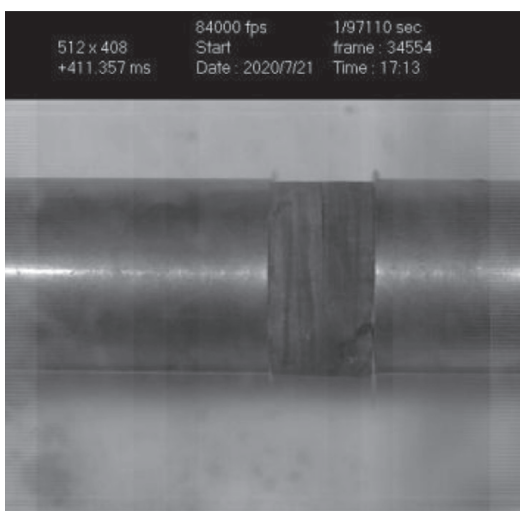

(b)

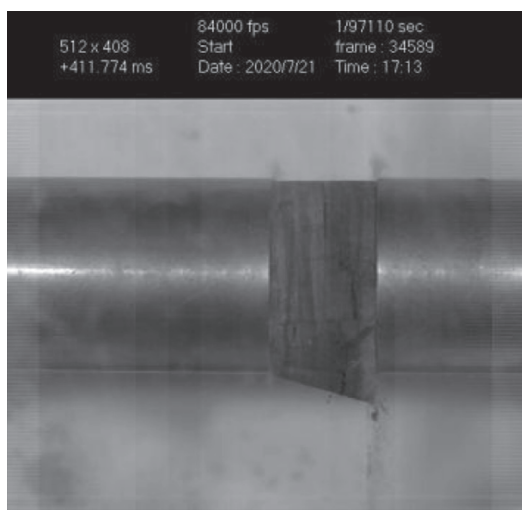

(e)

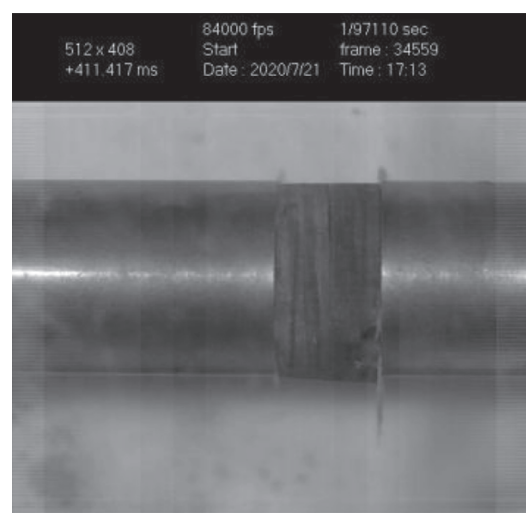

(c)

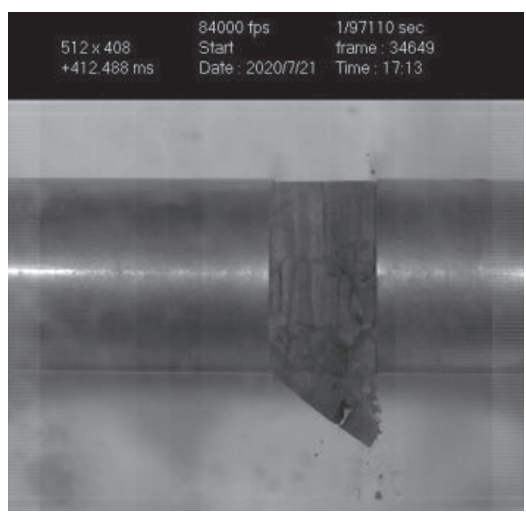

(f)

Figure 13: Failure of crack specimen filled with epoxy resin. (a) 0 us, (b) 95 us, (c) 155 us, (d) 202 us, (e) 512 us, and (f) 1226 us. 


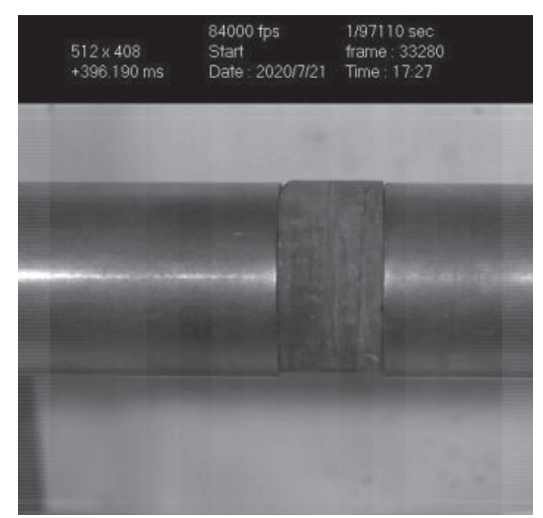

(a)

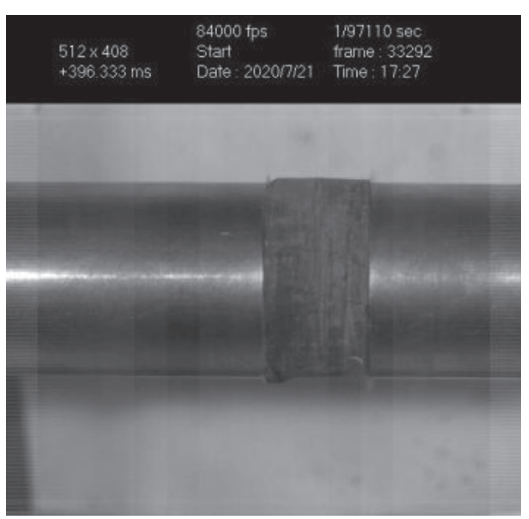

(d)

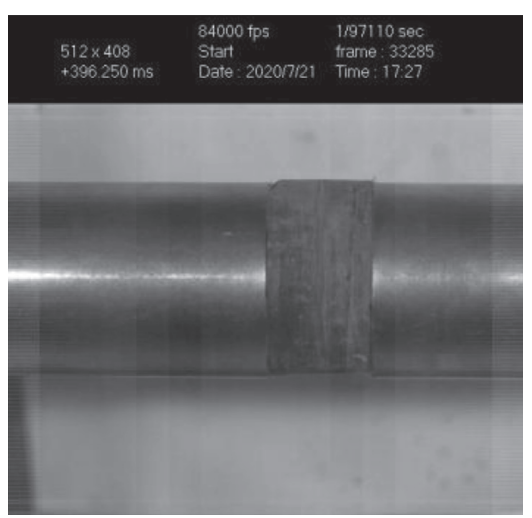

(b)

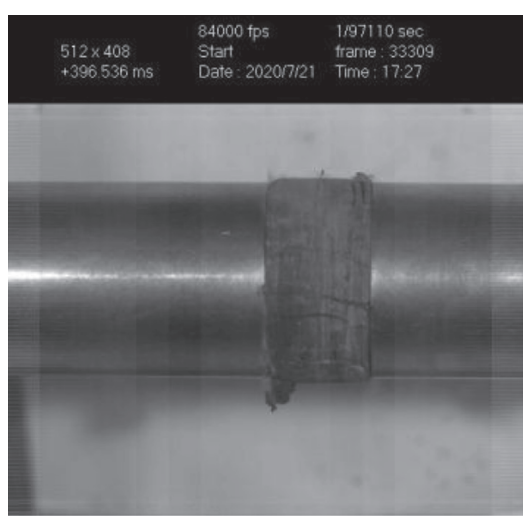

(e)

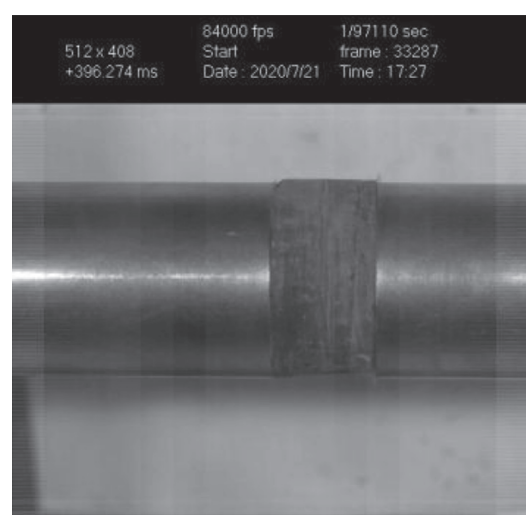

(c)

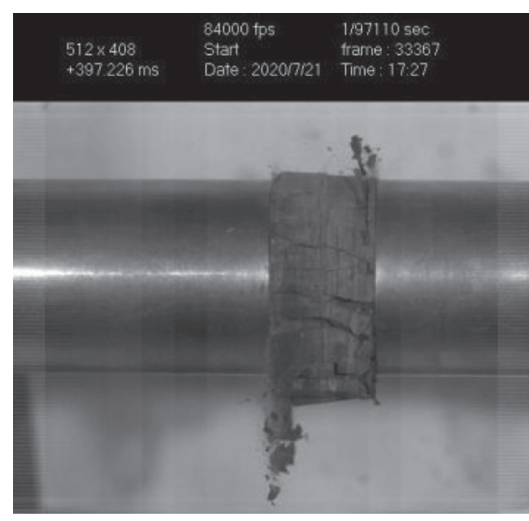

(f)

Figure 14: Failure of fracture specimen filled with cement (0.4 MPa). (a) 0 us, (b) 60 us, (c) 84 us, (d) 143 us, (e) 346 us, and (f) 1036 us.

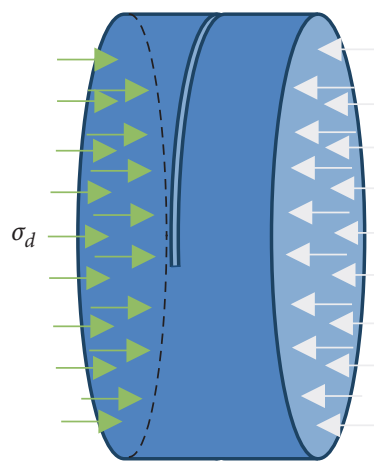

(a)

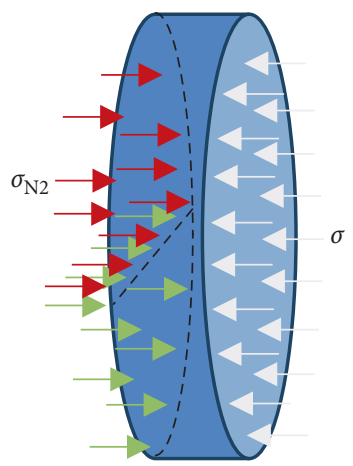

(c)

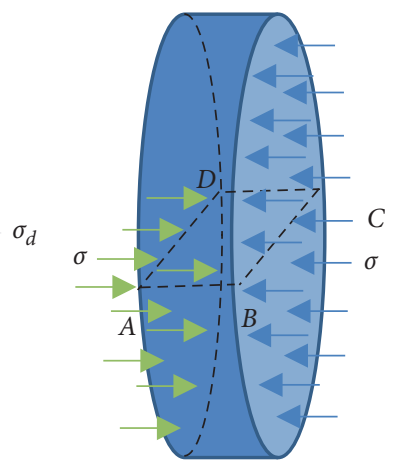

(b)

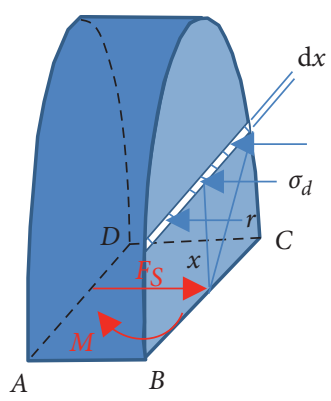

(d)

Figure 15: Force analysis. 


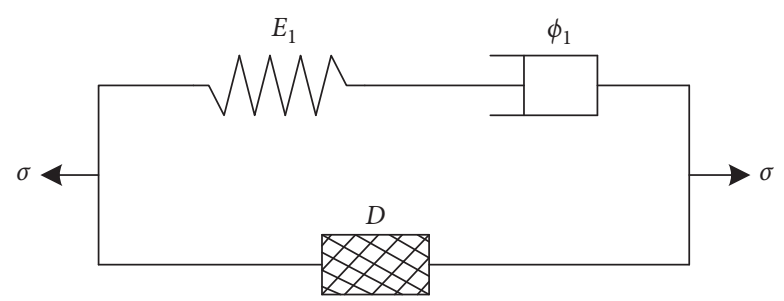

Figure 16: Improved damaged ZWT model.

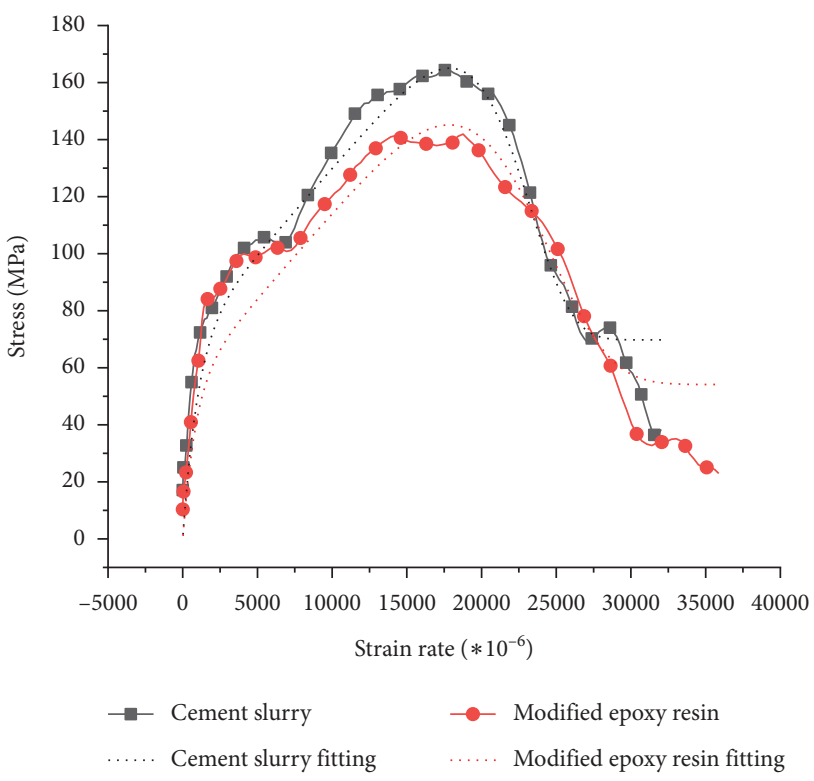

FIGURE 17: Fitting of stress-strain.

where $N_{f}$ is the number of already damaged microelements and $N$ is the total number of microelements.

The statistical damage model can be obtained through integral computation:

$$
D=1-\exp \left[-\left(\frac{\varepsilon}{F_{0}}\right)^{m}\right]
$$

According to the constitutive models of damage body (follow Weibull distribution) and Maxwell body and given the loading at constant strain rate can be realized in the SHPB test, it is never difficult to acquire the constitutive relation of the viscous-elastic damage model as follows:

$$
\sigma(\varepsilon)=E_{0} \varepsilon \cdot \exp \left[-\left(\frac{\varepsilon}{F_{0}}\right)^{m}\right]+E_{1} \varphi_{1} \dot{\varepsilon} \cdot\left[1-\exp \left(\frac{\varepsilon}{\varphi_{1} \dot{\varepsilon}}\right)\right],
$$

where $E_{0}$ is the elastic model before the damage body is damaged; $E_{1}$ is the spring stiffness of the Maxwell body; $\dot{\varepsilon}$ is the test strain rate; and $\varphi_{1}$ is the relaxation time.

For verifying the adaptability of the constitutive relation of the viscous-elastic damage model, this formula was used to fit the fractured rock reinforced by cement slurry grouting at a strain rate of $294 \mathrm{~s}^{-1}$ with the fractured rock reinforced by epoxy resin grouting at a strain rate of $237 \mathrm{~s}^{-1}$, the fitted curves are shown in Figure 17, and fitting parameters are listed in Table 6 . It could be seen that the constitutive
TABLE 6: Fitting parameters.

\begin{tabular}{lccccccc}
\hline $\begin{array}{l}\text { Grouting } \\
\text { materials }\end{array}$ & $E_{0} / \mathrm{MPa}$ & $F_{0}$ & $m$ & $E_{1} / \mathrm{MPa}$ & $\varphi_{1} / \mathrm{us}$ & $\dot{\varepsilon}$ & $R^{2}$ \\
\hline $\begin{array}{l}\text { Cement } \\
\text { slurry }\end{array}$ & 6.01 & 0.023 & 8.4 & 69.2 & 3.431 & 294 & 0.93067 \\
\hline $\begin{array}{l}\text { Modified } \\
\text { epoxy resin }\end{array}$ & 6.01 & 0.024 & 6.1 & 62.9 & 3.631 & 237 & 0.88033 \\
\hline
\end{tabular}

relation of the viscous-elastic damage model could be used to describe the mechanical behaviors of the grouting reinforced fractured rock mass under the action of impact load.

\section{Conclusion}

A fracture ( $0.2 \mathrm{~mm}$ in width) was cut from the intact sandy mudstone specimen, and then a fractured specimen was manually fabricated. Epoxy resin slurry and cement slurry were grouted into the fracture to simulate the fracture filling through grouting and investigate the reinforcement mechanisms of different grouting materials for fractured specimens. The failure processes of the specimens were recorded using a high-speed camera. To sum up, the following conclusions were drawn:

(1) The peak impact strength of each specimen has a natural logarithmic linear relation with the punch speed. With the increase of the impact speed, the dynamic specific strength of the modified epoxy resin grouting increases from 0.85 to 1.01 and decreases from 1.78 to 0.95 for the fractured specimen filled with cement slurry, manifesting that the fracture repair effect of modified epoxy resin is better than that of cement slurry. However, under lowspeed impact, the strength of the fractured sandy mudstone filled with cement slurry is higher than that of the specimen filled with modified epoxy resin.

(2) The strain rate of each specimen presented a linear relation with punch speed. With the increase of the impact speed, the specific strain rate of the modified epoxy resin grouting decreased from 1.09 to 1.04 and increased from 0.60 to 0.98 for the fractured specimen filled with cement slurry, meaning that the intactness of the specimen filled with modified epoxy resin was superior to that of the specimen filled with cement slurry. The specific strain rate of the latter showed stronger sensitivity to the impact speed with more obvious change, while that of the former was 
always approximate to 1 , indicating approximate properties of repaired rock to the intact rock.

(3) The ZWT model was improved, and a viscous-elastic damage model with one damage body and one Maxwell body in series connection was adopted, as it could realize a good fitting effect on the stress-strain curves of grouting reinforced fractured rock masses under the impact load.

\section{Data Availability}

All data, models, and code generated or used during the study appear in the submitted article.

\section{Conflicts of Interest}

The authors declared that they have no conflicts of interest to this work.

\section{Acknowledgments}

The authors would like to extend sincere gratitude to the National Key R\&D Program (grant no. 2017YFC0603003), National Natural Science Foundation Program (grant nos. 51974009, 51774012, 51674008, and 51974007), Key Research and Development Projects in Anhui Province (201904a07020010), Funding for Scientific Research Activities of Academic and Technological Leaders in Anhui Province (2018d187), Funding Project for Outstanding and Top-Notch Talent Training in Colleges and Universities (grant no. gxbjZD2016051), Leading Talent Program of "Provincial Special Funding Program" in Anhui Province, and Innovation Team Construction Project of the Scientific Research Platform for Colleges and Universities in Anhui for funding our scientific research activity, and to the State Key Laboratory of Mining Response and Disaster Prevention and Control in Deep Coal Mines for providing SHPB equipment.

\section{References}

[1] F. Dong, H. Song, and Z. Guo, "Support theory of roadway surrounding rock loose circle," Journal of China Coal Society, vol. 19, no. 1, pp. 21-32, 1994.

[2] N. Zhang and C. Hou, "Mechanical properties of broken rock after grouting reinforcement," Rock and Soil Mechanics, vol. 19 , no. 3, pp. 50-53, 1998.

[3] Q. Liu, G. Lei, and C. Lu, "Experimental study of grouting reinforcement influence on mechanical properties of rock fracture," Chinese Journal of Rock Mechanics and Engineering, vol. 36, no. S1, pp. 3140-3147, 2017.

[4] Z. Wang, L. Li, and C. Wang, "Experimental study on failure of cracked rock-like material after grouting reinforcement," Journal of Central South University, vol. 49, no. 4, pp. 957-963, 2018.

[5] H.-L. Le and S. R. Sun, "Effect of grouting materials and inclination angle of pre-existing flaw on uniaxial compressive strength and failure mode of rock-like specimens," Rock and Soil Mechanics, vol. 39, no. s1, pp. 211-219, 2018.

[6] G. Li, C. Sun, Y. Sun et al., "Macroscopic and microcosmic consolidation law of loose coal grouting based on the "two media-three interfaces" model," Journal of China Coal Society, vol. 44, no. 2, pp. 427-434, 2019.

[7] S. Li, R. Liu, Q. Zhang et al., "Research on C-S slurry diffusion mechanism with time-dependent behavior of viscosity," Chinese Journal of Rock Mechanics and Engineering, vol. 32, no. 12, pp. 2415-2421, 2013.

[8] J. Wei, B. Yao, Y. Liu et al., "Grouting fluid diffusion law and variable mass seepage model for frac-tured coal," Journal of China Coal Society, vol. 45, no. 1, pp. 204-212, 2020.

[9] S. Li, R. Liu, Q. Zhang, and X. Zhang, "Protection against water or mud inrush in tunnels by grouting: a review: a review," Journal of Rock Mechanics and Geotechnical Engineering, vol. 8, no. 5, pp. 753-766, 2016.

[10] L. Wang and T. Li, "The calculation of grouting diffusion radius on based bingham fluid for chunnel that passes through fractured rock mass," Applied Mechanics \& Materials, vol. 256-259, pp. 1280-1286, 2013.

[11] C. Zhang, J. Yang, and G. Zhang, "Experiment and application research on stability performance of filling grouting slurry," Chinese Journal of Rock Mechanics and Engineering, vol. 37, no. s1, pp. 3604-3612, 2018.

[12] Z. Shi, L. Fan, and Y. Song, "Study on properties of cementbased grouting material in high temperature," Chinese Journal of Underground Space and Engineering, vol. 14, no. 4, pp. 974-980, 2018.

[13] W. Li, F. U. A. Shaikh, L. Wang et al., "Experimental study on shear property and rheological characteristic of superfine cement grouts with nano-SiO addition," Construction and Building Materials, vol. 228, Article ID 117046, 2019.

[14] X. Guan, H. Zhang, and Z. Yang, "Research of high performance inorganic-organic composite grouting materials," Journal of China Coal Society, vol. 45, no. 3, pp. 902-910, 2020.

[15] S. Fei, S. Li, R. Liu, Q. Zhang, Z. Li, and H. Liu, "Performance and engineering application of effective microfine cementbased grout (EMCG) for water-rich sand strata," Chinese Journal of Rock Mechanics and Engineering, vol. 38, no. 7, pp. 1420-1433, 2019.

[16] J. Zhan and L. I. Tao, "SHPB tests and numerical simulation of dynamic behavior of grouting-reinforced fractured mudstone," Rock and Soil Mechanics, vol. 38, no. 7, pp. 2096-2102, 2017.

[17] Y. X. Zhou, K. Xia, X. B. Li, H. B. Li, and F. Dai, "Suggested methods for determining the dynamic strength parameters and mode-i fracture toughness of rock materials," International Journal of Rock Mechanics and Mining Sciences, vol. 49, pp. 105-112, 2002.

[18] J. M. Lifshitz and H. Leber, "Data processing in the split Hopkinson pressure bar tests," International Journal of Impact Engineering, vol. 15, no. 6, pp. 723-733, 1994.

[19] X. Li, Z. Zhou, T.-S. Lok et al., "Innovative testing technique of rock subjected to coupled static and dynamic loads," International Journal of Rock Mechanics and Mining Sciences, vol. 45, no. 5, pp. 739-748, 2008.

[20] Z. C. Hong, Q. Z. Zhang, and J. Peng, "Effect of thermal treatment on the basic friction angle of rock joint," Rock Mechanics and Rock Engineering, vol. 53, no. 4, pp. 1973-1990, 2020.

[21] Z. C. Tang, Q. Z. Zhang, J. Peng, and Y. Y. Jiao, "Experimental study on the water-weakening shear behaviors of sandstone joints collected from the middle region of Yunnan province P. R. China," Engineering Geology, vol. 258, Article ID 105161, 2020.

[22] Z. C. Tang, "Experimental investigation on temperature-dependent shear behaviors of granite discontinuity," Rock 
Mechanics and Rock Engineering, vol. 53, no. 9, pp. 40434060, 2020.

[23] Z. Tang and Y. Jiao, "Choosing appropriate appraisal to describe peak spatial features of rock joint profiles," International Journal of Geomechanics, vol. 20, no. 4, Article ID 04020021, 2020.

[24] Z. Tang, Dynamic Mechanical Properties of Epoxy Resin Under High Strain Rate, University of Science and Technology of China, Hefei, China, 1981, in Chinese.

[25] K. Imai and H. Lehmann, "The oxygen affinity of haemoglobin Tak, a variant with an elongated beta chain," Biochimica et Biophysica Acta, vol. 412, no. 2, pp. 288-294, 1975, in Chinese.

[26] S. Hu and D. Wang, "Dynamic constitutive relation of concrete under impact," Explosion and Shockwave, vol. 22, no. 3, pp. 242-246, 2002.

[27] L. Xie, G. Zhao, and X. Meng, "Research on damage viscoelastic dynamic constitutive model of soft rock and concrete materials," Chinese Journal of Rock Mechanics and Engineering, vol. 32, no. 4, pp. 857-864, 2013.

[28] R. Shan, R. Cheng, and W. Gao, "Study on dynamic constitutive model of anthracite of Yunjialing coal mine," Chinese Journal of Rock Mechanics and Engineering, vol. 25, no. 11, pp. 2258-2263, 2006.

[29] L. Miao, Experomental Studieds of Dynamic Constitutive Properties of Jointed Rock Masses: Analysis of Stress Waves, University of Science and Technology, Beijing, China, 2018, in Chinese.

[30] J. Zhu, X. Li, and F. Gong, "Dynamic characteristics and damage model for rock under uniaxial cyclic impact compressive loads," Chinese Journal of Geotechnical Engineering, vol. 35, no. 3, pp. 531-539, 2013. 